\title{
Testing for the Endogenous Nature between Women's Empowerment and Antenatal Health Care Utilization: Evidence from a Cross-Sectional Study in Egypt
}

\author{
Hassan H. M. Zaky, ${ }^{1,2}$ Dina M. Armanious, ${ }^{2}$ and Mohamed Ali Hussein ${ }^{3}$ \\ ${ }^{1}$ School of Humanities and Social Sciences, The American University in Cairo and Social Research Center of The American University \\ in Cairo, New Cairo 11835, Egypt \\ ${ }^{2}$ Department of Statistics, Faculty of Economics and Political Science, Cairo University, Giza 12613, Egypt \\ ${ }^{3}$ Faculty of Commerce, South Valley University, Qena 83523, Egypt
}

Correspondence should be addressed to Hassan H. M. Zaky; hzaky@aucegypt.edu

Received 4 February 2014; Accepted 7 July 2014; Published 22 July 2014

Academic Editor: Joseph Telfair

Copyright ( 2014 Hassan H. M. Zaky et al. This is an open access article distributed under the Creative Commons Attribution License, which permits unrestricted use, distribution, and reproduction in any medium, provided the original work is properly cited.

\begin{abstract}
Women's relative lack of decision-making power and their unequal access to employment, finances, education, basic health care, and other resources are considered to be the root causes of their ill-health and that of their children. The main purpose of this paper is to examine the interactive relation between women's empowerment and the use of maternal health care. Two model specifications are tested. One assumes no correlation between empowerment and antenatal care while the second specification allows for correlation. Both the univariate and the recursive bivariate probit models are tested. The data used in this study is EDHS 2008. Factor Analysis Technique is also used to construct some of the explanatory variables such as the availability and quality of health services indicators. The findings show that women's empowerment and receiving regular antenatal care are simultaneously determined and the recursive bivariate probit is a better approximation to the relationship between them. Women's empowerment has significant and positive impact on receiving regular antenatal care. The availability and quality of health services do significantly increase the likelihood of receiving regular antenatal care.
\end{abstract}

\section{Introduction}

In 2000, at the millennium summit, all 191 United Nations member states signed the millennium declaration which sets eight Millennium Development Goals (MDGs) to be achieved by the year 2015. The fifth Millennium Development Goal calls for improving maternal health care and includes a target of reducing the maternal mortality ratio by three quarters between 1990 and 2015 and achieving universal access to reproductive health through antenatal care coverage. If the world achieves the fifth Millennium Development Goal by 2015, more than two million women will survive childbirth [1]. Most maternal and child deaths are preventable and avoidable with reproductive health services.

Women's relative lack of decision-making power and their unequal access to employment, finances, education, basic health care, and other resources are considered to be the root causes of their ill-health and that of their children [2]. Empowering women is critical to advancing human development and achieving progress towards the MDGs.

The International Conference on Population and Development (ICPD 1994) in Cairo emphasized that women should be empowered to practice control over their health and reproductive rights. Additionally, this conference stated that the level of antenatal and postnatal care is affected by the availability of health services and the demand by pregnant women and mothers for these services [3]. The Women Deliver Conference [4], held in London in October 2007, demonstrated that maternal and newborn health is a key factor to the economic growth and the social fabric of the developing nations. It emphasized that gender equality and women's empowerment are critical for development efforts 
to reduce poverty, improve health, and achieve economic stability and growth.

Traditionally, women's empowerment and the use of antenatal health care are analyzed separately. Studies identified socioeconomic and demographic determinants of antenatal health care utilization among women in Egypt $[5,6]$. Other studies discussed the determinants of women's empowerment in Egypt [7, 8]. Some other studies examined the impact of women's empowerment on antenatal health care utilization [9-11]. Our review of these studies confirmed that the simultaneous relationship between empowerment and antenatal health care has not been studied in Egypt. To fill this gap, the study aims to model and identify the interactive relationship between women's empowerment and the use of antenatal health care. The study explores if women's empowerment and antenatal health care utilization are dependently determined or not. Both the univariate probit and the recursive bivariate probit models are utilized to test this hypothesis.

\section{Data and Methods}

2.1. Data. The study depends on data derived from Egypt Demographic and Health Survey [12]. This survey was conducted on behalf of the Ministry of Health $(\mathrm{MoH})$, by El Zanaty and associates. The EDHS 2008 covered a representative sample of 16,527 ever married women in the age group of 15-49 years. Only married women aged 1549 whose last birth was during the five-year period before the survey are included in the analysis because data about antenatal care was collected from this subsample only. They amounted to 8036 women.

Table 1 presents the distribution of married women whose last birth was in the five-year period before the survey according to some of their background characteristics. The majority of women (62 percent) are living in rural areas. Looking at the age distribution in Table 1, around three-fifths of those women are under the age of 30 . There are few women who are aged 40 and over.

Regarding the educational level of women and their husbands, one-quartile of women never attended school, while 16 percent of husbands have never attended school. Moreover, more than half of women (52 percent) and 56 percent of husbands have completed at least the secondary level. Data of Table 1 shows that 12 percent of ever married women were working for cash at the time of the survey. Women were fairly evenly distributed across the wealth quintiles.

\subsection{Methods}

2.2.1. Model Specification. Two model specifications are tested in the study. The first assumes that there is no correlation between women's empowerment and use of regular antenatal care and that women's empowerment is exogenously determined. This approach uses the univariate probit model. The second assumes that the two outcome variables are dependently determined and that the relationship is recursive. The recursive bivariate probit model is tested.
TABLE 1: Distribution of married women whose last birth was during the five-year period preceding the survey according to women's background characteristics, 2008.

\begin{tabular}{|c|c|c|}
\hline Items & Percentage & Number \\
\hline \multicolumn{3}{|l|}{ Place of residence } \\
\hline Urban & 38.2 & 3020 \\
\hline Rural & 61.8 & 5016 \\
\hline \multicolumn{3}{|l|}{ Region } \\
\hline Urban governorates & 16.4 & 1075 \\
\hline Urban lower Egypt & 10 & 712 \\
\hline Rural lower Egypt & 34.3 & 2282 \\
\hline Urban upper Egypt & 10.8 & 945 \\
\hline Rural upper Egypt & 27.1 & 2564 \\
\hline Frontier governorates & 1.4 & 458 \\
\hline Current age 15-19 & 3.5 & 276 \\
\hline $20-24$ & 24.4 & 1943 \\
\hline $25-29$ & 33.7 & 2631 \\
\hline $30-34$ & 20.9 & 1724 \\
\hline $35-39$ & 11.7 & 963 \\
\hline $40-44$ & 4.9 & 416 \\
\hline $45-49$ & 0.9 & 83 \\
\hline \multicolumn{3}{|l|}{ Educational attainment } \\
\hline No education & 25.3 & 2186 \\
\hline Incomplete primary & 6.7 & 553 \\
\hline Complete primary & 3.5 & 268 \\
\hline Incomplete secondary & 12.2 & 983 \\
\hline Complete secondary & 39.3 & 3073 \\
\hline Higher & 13 & 973 \\
\hline \multicolumn{3}{|l|}{ Work status } \\
\hline Not working for cash & 88.4 & 7100 \\
\hline Working for cash & 11.6 & 936 \\
\hline \multicolumn{3}{|l|}{ Reading newspaper } \\
\hline No & 76.2 & 6168 \\
\hline Yes & 23.8 & 1868 \\
\hline \multicolumn{3}{|l|}{ Watching TV } \\
\hline No & 2.8 & 284 \\
\hline Yes & 97.2 & 7752 \\
\hline \multicolumn{3}{|l|}{ Listening to radio } \\
\hline No & 40.1 & 3453 \\
\hline Yes & 59.9 & 4583 \\
\hline \multicolumn{3}{|l|}{ Wealth index } \\
\hline Poorest & 19.3 & 1767 \\
\hline Poorer & 19.7 & 1641 \\
\hline Middle & 21 & 1669 \\
\hline Richer & 20.6 & 1515 \\
\hline Richest & 19.4 & 1444 \\
\hline \multicolumn{3}{|c|}{ Partner's educational attainment } \\
\hline No education & 16 & 1363 \\
\hline Incomplete primary & 10.6 & 868 \\
\hline Complete primary & 5.1 & 387 \\
\hline Incomplete secondary & 12.5 & 976 \\
\hline Complete secondary & 39.5 & 3223 \\
\hline Higher & 16.3 & 1219 \\
\hline Total & 100 & 8036 \\
\hline
\end{tabular}

The probit model is used because both variables, receiving regular antenatal care and women's empowerment, are binary. 
For antenatal care, it takes the value 1 if the number of antenatal care visits is at least 4 and takes the value 0 if the number of visits is less than 4 . For empowerment, this study constructs a composite indicator to express women's empowerment. Previous literature shows that creation of women's empowerment indicators are implemented by the sums of binary input variables. Women are scored one for answers to each variable that contributed to a higher degree of empowerment; otherwise they are scored zero [7-9]. However, there are other researchers who used Factor Analysis Technique to create women's empowerment indicators [13, 14]. This study will depend on the first method to create women's empowerment indicator.

The variables used to construct women's empowerment indicator are the participation of women in making decision about major household purchases, namely, daily household purchases, her health care, visiting family or relatives, how her husband's earnings and her money are used, and the use of contraception. In addition, there are some other variables which represent whether or not it is a big problem for women to go to the doctor alone or even to get a permission to go to the doctor. Internal consistency among all these variables was moderate (Cronbach's Alpha $=0.59$ ).

An index is created using the sums of the nine binary variables to construct the indicator of women's empowerment (equal weights are given to the nine variables used to construct the indicator of women's empowerment). It ranged from 0 to 9 according to the responses of the respondents on the nine questions. The range of the responses is classified equally to two groups. According to this classification, woman is not empowered if the value of the index is from 0 to 4 and she is empowered if the index value is from 5 to 9 . Categories from 0 to 4 are merged to be " 0 " and this means that woman is not empowered, and categories from 5 to 9 are merged to be " 1 " and this means that woman is empowered.

The explanatory variables are the place of residence, region, work status, age, wealth index, women's education, exposure to media (newspaper, TV, and radio), husband's education, and availability and quality of health services. Description of these variables is shown in Table 1 except for the availability and quality of health services. These two variables need special treatment as they are not readily available in the data used. The study constructs composite indicators to express them. These composite indicators are created by Exploratory Factor Analysis technique (EFA). There are several methods for obtaining factor extraction and rotation [15]. This study uses principal component as an extraction method and VARIMAX as a rotation method.

In 2008 EDHS, women were asked to mention whether or not there is a problem on some issues related to the availability of health services. These issues are about distance to the health facility, having to take transportation, and availability of female health provider. The indicator of availability of health services is constructed using these variables and by applying the Factor Analysis Technique. One factor is extracted and this factor explains about 59 percent of the total variations among the data and it represents the availability of health services. Internal consistency among these variables was moderate (Cronbach's Alpha $=0.56)$.
TABLE 2: Rotated factor loadings of quality of health services.

\begin{tabular}{lcc}
\hline \multirow{2}{*}{ Variables } & \multicolumn{2}{c}{ Factors } \\
& First & Second \\
\hline Blood pressure measured & $\mathbf{0 . 7 8 2}$ & 0.099 \\
Blood sample taken & $\mathbf{0 . 7 9 9}$ & 0.186 \\
Urine sample taken & $\mathbf{0 . 8 0 1}$ & 0.176 \\
Weight & $\mathbf{0 . 7 8 2}$ & 0.071 \\
Told about the signs of pregnancy complications & 0.158 & $\mathbf{0 . 7 7 6}$ \\
Given any iron tablets or syrup & 0.099 & $\mathbf{0 . 8 0 4}$ \\
\hline
\end{tabular}

Similarly, women who reported that they received antenatal care, tetanus toxoid injections, or other medical care unrelated to the pregnancy are asked whether they were weighed, their blood pressure measured, and urine and blood samples taken during any of the visits they made to a medical provider during their pregnancy. Those women are also asked whether they had been told about the signs of pregnancy complications, and, if they were told, whether they received any information about where to go if they experienced any complications. Finally, women are also asked whether they were given or had bought iron tablets or syrup [12]. Using these variables, Factor Analysis Technique is also used to construct the indicators of quality of health services. Two factors are extracted and they explain about 65 percent of the total variations among the data. Table 2 shows the rotated factor loadings for these factors. Internal consistency among all these variables was high (Cronbach's Alpha $=0.74$ ).

The results of the factor analysis show that the first factor includes the following four variables: blood and urine samples were taken, blood pressure was measured, and woman was weighted. This factor explains about 47 percent of the variation and it represents "content of antenatal care." The second factor includes the following three variables: woman was told about the signs of pregnancy complications, was told where to go if she had any of these complications, and was given or bought any iron tablets or syrup. This factor explains about 18 percent of the variation and it represents "treatment with complications."

Our second specification relies on the bivariate probit model which is a joint model for two binary outcomes that are allowed to be correlated with each other. Greene [16] shows that estimators from the bivariate probit model become consistent and efficient when the dependent variables in the two-equation model are binary, and omitted variables are correlated with each other. Maddala (1983) listed the bivariate probit model with endogenous dummy model among the recursive models. The recursive structure builds on a first reduced form equation for the potentially endogenous dummy and a second structural form equation determining the outcome of interest:

$$
\begin{gathered}
Y_{1 i}^{*}=\widetilde{\beta}_{1} X_{1 i}+u_{1 i} \\
Y_{2 i}^{*}=\widetilde{\beta}_{2} X_{2 i}+u_{2 i}=\delta_{1} Y_{1 i}+\widetilde{\delta}_{2} Z_{2 i}+u_{2 i},
\end{gathered}
$$


where $Y_{1 i}^{*}$ and $Y_{2 i}^{*}$ are latent variables, and $Y_{1 i}$ and $Y_{2 i}$ are binary variables following the rule

$$
Y_{L i}=\left\{\begin{array}{ll}
1 & \text { if } Y^{*}>0 \\
0 & \text { if } Y^{*} \leq 0 ;
\end{array} \quad L=1,2 .\right.
$$

$X_{1 i}$ and $Z_{2 i}$ are vectors of exogenous variables, $\beta_{1}$ and $\delta_{2}$ are parameter vectors, $\delta_{1}$ is a scalar parameter, and $\widetilde{\beta}_{2}=\left(\delta_{1} \widetilde{\delta}_{2} \widetilde{ }\right.$. In the second specification, the error terms are assumed to be independently and identically distributed as bivariate normal [17].

In the study, $Y_{1}$ refers to women's empowerment and $Y_{2}$ is receiving regular antenatal health care. $Y_{1}^{*}$ is a latent variable which denotes the level of women's empowerment. $Y_{2}^{*}$ is a latent variable which denotes the probability that the woman will receive regular antenatal health care.

The exogeneity test in the recursive bivariate probit model arises from allowing the correlation between the error terms $\left(u_{1 i}\right.$ and $\left.u_{2 i}\right)$ to be nonzero. The exogeneity test can be constructed from the following null and alternative hypotheses:

$$
\mathrm{H}_{0}: \rho=0, \quad \mathrm{H}_{\mathrm{a}}: \rho \neq 0,
$$

where $\rho$ is the coefficient of correlation between the residuals from (1). $\mathrm{H}_{0}$ corresponds to the assumption of exogeneity of women's empowerment variable in the antenatal care equation [18].

\section{Results}

The study estimates both the univariate and recursive bivariate probit models and the results are shown in Table 3. The univariate probit model assumes that women's empowerment is exogenously determined. According to the results of this model and unlike our a priori expectations, women's empowerment does not have any significant effect on receiving regular antenatal care.

Since the main objective of the study is to test the simultaneous nature between women's empowerment and receiving antenatal care, so the recursive bivariate probit model is estimated. The estimation results and the exogeneity test, shown in Table 3, provide significant evidence in favor of supporting a simultaneous relationship between women's empowerment and receiving regular antenatal care (the likelihood ratio test is significant with $P$ value less than 10 percent). This confirms our a priori expectations that receiving regular antenatal care and women's empowerment are simultaneously determined and that the recursive bivariate probit model specification is a better representation of this relationship than the univariate probit model. The results of the recursive bivariate probit, shown in Table 3, demonstrate that women's empowerment increases the probability of receiving at least four antenatal care visits at less than $5 \%$ significance level.

The results also report the effects of other socioeconomic variables on receiving regular antenatal care. There is a significant relationship between both women's education and husband's education and receiving regular antenatal care. Women who have achieved secondary or higher education are more likely to receive at least four antenatal care visits compared with women who have never attended school. Moreover, women whose husbands have achieved secondary education or higher are more likely to receive regular antenatal care compared with those whose husbands have never attended school.

Table 3 indicates that wealth index significantly increases the likelihood of receiving regular antenatal care. Woman from the richest quintile is more likely to receive regular antenatal care compared with woman from the poorest quintile. Additionally, it can be noticed that women's work status has a significant impact on receiving regular antenatal care. Women who work for cash are more likely to receive at least four antenatal care visits compared with women who do not work for cash.

The findings of this study show that the availability of health services significantly increases the likelihood of receiving regular antenatal care. Additionally, the higher the level of indicators of quality of health services is, the more likely the women will receive at least four antenatal care visits.

Table 3 also provides the determinants of women's empowerment estimated by the recursive bivariate probit model. Data of Table 3 shows that women's age is positively correlated with women's empowerment. Additionally, women's education is associated with higher women's empowerment, implying the possibility that women who have achieved secondary or higher education are more empowered than those who have never attended school. Women's working status contributes to the higher level of women's empowerment, suggesting that women who work for cash are more empowered than those who do not work for cash.

The results indicate that exposure to the media significantly increases the likelihood of women's empowerment. Table 3 shows that women who are reading newspapers or watching television are more likely to get involved into decision-making processes, compared with women who are not reading newspapers or watching television. Figure 1 summarizes the basic results of the recursive bivariate model.

\section{Discussion}

The findings reveal that receiving regular antenatal care and women's empowerment are simultaneously determined and therefore the recursive bivariate probit model specification is more appropriate than the two separate univariate probit models. This result is in agreement with the findings from Tajikistan [19]. Additionally, the study shows that women's empowerment increases the probability that the woman receives at least four antenatal care visits.

The findings of this study show that wealth index significantly increases the likelihood of receiving regular antenatal care. This result is consistent with evidence from Ahmed [6] and Bloom et al. [9], who argued that women who are wealthy were more likely to attend antenatal care than those from poorer households.

The results show that women's education is correlated with receiving regular antenatal care. As from literature in Tajikistan, it is proved that women who have achieved 
TABLE 3: Univariate and recursive bivariate probit model estimates: results of the two specifications.

\begin{tabular}{|c|c|c|c|c|c|c|}
\hline \multirow{3}{*}{ Variables } & \multirow{2}{*}{\multicolumn{2}{|c|}{$\begin{array}{c}\text { Univariate probit } \\
\text { Regular ANC }\end{array}$}} & \multicolumn{4}{|c|}{ Recursive bivariate probit } \\
\hline & & & \multicolumn{2}{|c|}{ Regular ANC } & \multicolumn{2}{|c|}{ Women's empowerment } \\
\hline & Coef. & St. error & Coef. & St. error & Coef. & St. error \\
\hline Women's empowerment & -0.024 & 0.041 & $1.166^{* *}$ & 0.343 & & \\
\hline \multicolumn{7}{|l|}{ Place of residence } \\
\hline \multicolumn{7}{|l|}{ Rural (ref.) } \\
\hline Urban & -0.007 & 0.005 & 0.147 & 0.167 & $-0.282^{* *}$ & 0.135 \\
\hline \multicolumn{7}{|l|}{ Region } \\
\hline \multicolumn{7}{|l|}{ Urban governorates (ref.) } \\
\hline $\begin{array}{l}\text { Urban lower Egypt } \\
\text { Rural lower Egypt } \\
\text { Urban upper Egypt } \\
\text { Rural upper Egypt } \\
\text { Frontier governorates }\end{array}$ & $\begin{array}{c}-0.129 \\
-0.333^{*} \\
-0.309^{*} \\
-0.519^{*} \\
-0.175^{* * *}\end{array}$ & $\begin{array}{l}0.089 \\
0.071 \\
0.080 \\
0.074 \\
0.100\end{array}$ & $\begin{array}{c}-0.039 \\
-0.388^{* * *} \\
-0.295^{*} \\
-0.750^{*} \\
-0.512^{*}\end{array}$ & $\begin{array}{c}0.096 \\
0.212 \\
0.078 \\
0.178 \\
0.115\end{array}$ & $\begin{array}{l}0.217^{* *} \\
0.375^{* *} \\
-0.096 \\
-0.142 \\
-0.619^{*}\end{array}$ & $\begin{array}{l}0.084 \\
0.146 \\
0.072 \\
0.145 \\
0.093\end{array}$ \\
\hline \multicolumn{7}{|l|}{ Wealth index } \\
\hline \multicolumn{7}{|l|}{ Poorest (ref.) } \\
\hline $\begin{array}{l}\text { Poorer } \\
\text { Middle } \\
\text { Richer } \\
\text { Richest }\end{array}$ & $\begin{array}{l}0.206^{*} \\
0.327^{*} \\
0.573^{*} \\
0.820^{*}\end{array}$ & $\begin{array}{l}0.051 \\
0.056 \\
0.066 \\
0.082\end{array}$ & $\begin{array}{l}0.173^{* *} \\
0.285^{*} \\
0.540^{*} \\
0.737^{*}\end{array}$ & $\begin{array}{r}0.056 \\
0.066 \\
0.083 \\
0.118\end{array}$ & $\begin{array}{c}0.004 \\
0.006 \\
0.116^{* * *} \\
0.095\end{array}$ & $\begin{array}{l}0.051 \\
0.056 \\
0.066 \\
0.078\end{array}$ \\
\hline \multicolumn{7}{|l|}{ Reading newspaper } \\
\hline \multicolumn{7}{|l|}{ No (ref.) } \\
\hline Yes & 0.038 & 0.05 & $0.116^{* *}$ & 0.056 & $0.233^{*}$ & 0.049 \\
\hline \multicolumn{7}{|l|}{ Watching TV } \\
\hline \multicolumn{7}{|l|}{ No (ref.) } \\
\hline Yes & 0.013 & 0.093 & 0.130 & 0.092 & $0.252^{*}$ & 0.092 \\
\hline \multicolumn{7}{|l|}{ Listening to radio } \\
\hline \multicolumn{7}{|l|}{ No (ref.) } \\
\hline Yes & 0.014 & 0.036 & 0.022 & 0.033 & 0.039 & 0.036 \\
\hline \multicolumn{7}{|l|}{ Women's age } \\
\hline \multicolumn{7}{|l|}{ 15-24 (ref.) } \\
\hline $25-39$ & -0.084 & 0.057 & -0.045 & 0.057 & $0.174^{*}$ & 0.037 \\
\hline $40-49$ & 0.029 & 0.131 & 0.043 & 0.099 & $0.346^{*}$ & 0.079 \\
\hline \multicolumn{7}{|l|}{ Work status } \\
\hline \multicolumn{7}{|l|}{ Not working for cash } \\
\hline Working for cash & 0.058 & 0.063 & $0.215^{* *}$ & 0.085 & $0.529^{*}$ & 0.072 \\
\hline \multicolumn{7}{|l|}{ Women's education } \\
\hline \multicolumn{7}{|l|}{ No education (ref.) } \\
\hline Incomplete primary & $0.134^{* * *}$ & 0.071 & $0.179^{* *}$ & 0.066 & $0.146^{* *}$ & 0.070 \\
\hline Complete primary & 0.044 & 0.093 & 0.059 & 0.086 & 0.034 & 0.090 \\
\hline Incomplete secondary & $0.129^{* *}$ & 0.061 & $0.151^{* *}$ & 0.057 & 0.086 & 0.059 \\
\hline Complete secondary & $0.175^{* *}$ & 0.056 & $0.242^{*}$ & 0.052 & $0.201^{*}$ & 0.055 \\
\hline Higher & $0.295^{* *}$ & 0.095 & $0.385^{*}$ & 0.089 & $0.322^{*}$ & 0.094 \\
\hline Husband's education & & & & & & \\
\hline No education (ref.) & & & & & & \\
\hline Incomplete primary & 0.005 & 0.064 & -0.019 & 0.060 & -0.064 & 0.062 \\
\hline Complete primary & $0.158^{* * *}$ & 0.087 & 0.116 & 0.082 & -0.047 & 0.083 \\
\hline Incomplete secondary & 0.048 & 0.064 & 0.057 & 0.059 & 0.033 & 0.063 \\
\hline Complete secondary & 0.083 & 0.056 & $0.105^{* *}$ & 0.052 & 0.087 & 0.055 \\
\hline Higher & $0.259^{* *}$ & 0.082 & $0.268^{* *}$ & 0.077 & 0.127 & 0.079 \\
\hline Availability of health services & $0.038^{* *}$ & 0.017 & $0.029^{* *}$ & 0.015 & & \\
\hline Content of antenatal care & $0.396^{*}$ & 0.016 & $0.337^{*}$ & 0.049 & & \\
\hline
\end{tabular}


TABLE 3: Continued.

\begin{tabular}{lccccc}
\hline \multirow{2}{*}{ Variables } & \multicolumn{2}{c}{ Univariate probit } & \multicolumn{3}{c}{ Recursive bivariate probit } \\
& \multicolumn{2}{c}{ Regular ANC } & \multicolumn{2}{c}{ Regular ANC } & \multicolumn{2}{c}{ Women's empowerment } \\
& Coef. & St. error & Coef. & St. error & Coef. \\
\hline Treatment with complications & $0.279^{*}$ & 0.019 & $0.237^{*}$ & 0.039 & St. error \\
Constant & $0.645^{*}$ & 0.165 & $0.906^{* *}$ & 0.301 & $0.46^{* *}$ \\
Rho $(\rho)$ & & & -0.711 & 0.235 & \\
LR test & & & $3.506^{* * *}$ & & \\
\hline
\end{tabular}

Source: calculated by authors using EDHS, 2008.

${ }^{*}$ Significant at level $1 \% .{ }^{* *}$ Significant at level 5\%. ${ }^{* * *}$ Significant at level $10 \%$.

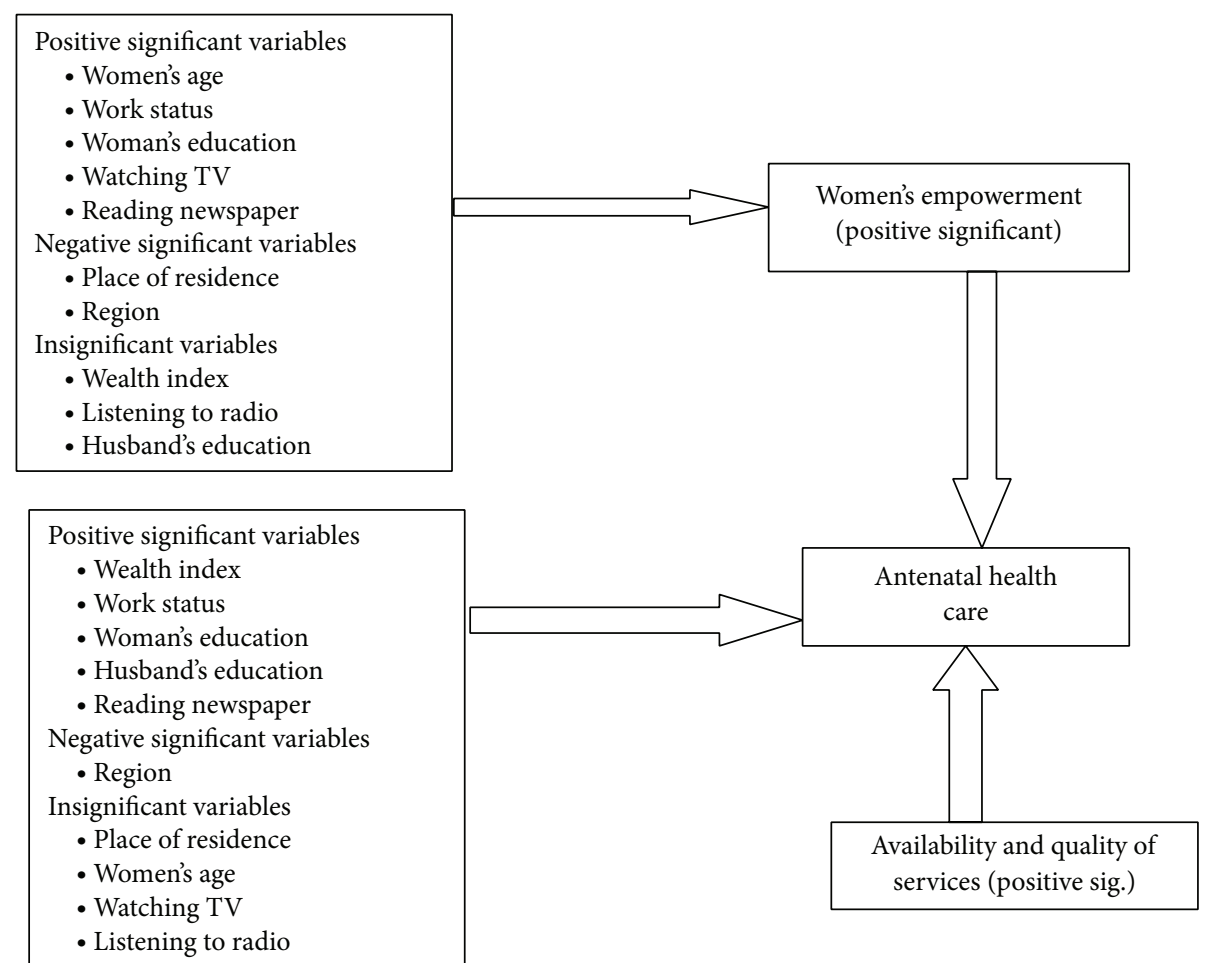

FIGURE 1: Summary results of the recursive bivariate model.

secondary or higher education are more likely to receive at least four antenatal care visits compared with women who have never attended school [19].

The study shows that the higher the level of indicators of quality of health services, the more likely the women to receive at least four antenatal care visits. This confirms a previous study by Zaky et al. [11] which showed that quality of health services has a positive impact on the number of antenatal care visits.

Similar to the results by Kamiya [19] in Tajikstan, one of the major findings is that women's working status is significantly ( $P$ value less than 1 percent) correlated with women's empowerment.

With regard to education, this study confirmed the findings of the study by Kamal [8] in Egypt showing that women's education plays an important role in raising the level of women's empowerment. Also, this study and another study by Shafei [7] in Egypt indicate that exposure to the media significantly increases the likelihood of women's empowerment.

4.1. Limitations of the Study. Because of data limitations, where women' empowerment module is limited to some questions, the analysis of future women empowerment studies could benefit from collecting additional data about women's role and activities such as participation in political life, violence at home, gender preference, getting a job and finance, and measuring their self-confidence to better capture all dimensions of women's empowerment. Also, this study lacked some variables related to availability and quality of health services, which are often considered key factors in the ability to seek services, such as number of opening hours for the facilities, waiting times at the health facility, providers' skills in counselling, and health education skills. Despite these limitations, this study tested for the first time the interactive relation between women's empowerment and the 
use of antenatal health care in Egypt using a recursive model. Accordingly, it provides important policy implications on the role of women's empowerment and its impact on women's health. In addition, the study uses the most recent available data based on a representative sample of ever married women aged 15-49 years in Egypt. Accordingly, the results are generalizable and are not limited.

\section{Concluding Remarks and Recommendations}

The study attempted to examine the interactive relation between women's empowerment and the use of maternal health care and whether women's empowerment and receiving regular antenatal care are simultaneously determined. The recursive bivariate probit model is used to achieve this goal. The findings of the model show that women's empowerment and receiving regular antenatal care are simultaneously determined. Furthermore, the findings confirm that women's empowerment is crucial in improving maternal health care in the developing countries.

Based on the main findings of the study, the following recommendations can be introduced.

(i) More efforts are needed to reduce inequity among Egyptian women.

(ii) More governmental efforts are suggested to target poor women and increase their awareness of the risks they might be exposed in order to encourage them to utilize antenatal health care services.

(iii) Awareness programs about antenatal care are advisable to target less educated women and inform them about the advantages of antenatal care utilization.

(iv) Collecting information about how women who had antenatal care are satisfied with the services offered to them and the problems they face during receiving the antenatal care.

(v) Collecting information about the complaints of antenatal health care services is important to solve these problems and improve the quality of the services.

(vi) Further research is needed, using more updated measures of women's empowerment, on the relationship between women's empowerment and antenatal health care utilization, which are advised to draw more robust empirical results.

\section{Conflict of Interests}

The authors declare that there is no conflict of interests regarding the publication of this paper.

\section{References}

[1] United Nations Development Programme, "A time for bold ambition together we can cut poverty in half," Annual Report, UNDP, New York, NY, USA, 2005, http://www.undp .org/annualreports/2005/english/IAR05-English.pdf.

[2] World Health Organization (WHO), Make Every Mother and Child Count, WHO, Geneva, Switzerland, 2005.
[3] Department for International Development (DFID), Poverty Elimination and Empowerment of Women: Strategies for Achieving the International Development Targets, DFID, London, UK, 2000.

[4] "Women Deliver Conference Overview 2007," 2011, http://www.womendeliver.org/.

[5] M. A. Mohamed, Some Aspects of Safe Motherhood in Egypt [M.S. thesis], CDC, Cairo, Egypt, 2003.

[6] S. M. Ahmed, Causes and consequences of maternal health in Egypt 2000 [M.S. thesis], Cairo Demographic Center, Cairo, Egypt, 2005.

[7] Z. R. Shafei, Women's empowerment impact on fertility and family planning in Egypt [M.Sc thesis], CDC, Cairo, Egypt, 2005.

[8] M. M. Kamal, Women's empowerment and child's health and education in Egypt [Ph.D. thesis], Institute of Statistical Studies and Research, Cairo University, Cairo, Egypt, 2006.

[9] S. S. Bloom, D. Wypij, and M. Das Gupta, "Dimensions of women's autonomy and the influence on maternal health care utilization in a North Indian City," Demography, vol. 38, no. 1, pp. 67-78, 2001.

[10] M. Furuta and S. Salway, "Women's position within the household as a determinant of maternal health care use in Nepal," International Family Planning Perspectives, vol. 32, no. 1, pp. 1727, 2006.

[11] H. Zaky, D. M. H, and M. A. Hussein, "Impact of Women's empowerment and Other Indicators on Antenatal Health Care Utilization in Egypt," in Proceedings of the Annual Meeting of Population Association of America (PAA '12), San Francisco, Calif, USA, 2012.

[12] F. El Zanaty and A. A. Way, Egypt Demographic and Health Survey 2008, Ministry of Health, El-Zanaty and Associates and Macro International, 2009.

[13] M. A. Hussein, Impact of Women's empowerment on the antenatal health care utilization [M.Sc thesis], Faculty of Economics and Political Science, Cairo University, Cairo, Egypt, 2009.

[14] S. Kishor, "Empowerment of women in egypt and links to the survival and health of their infants," in Women's Empowerment and Demographic Processes, Oxford University Press, New York, NY, USA, 2000.

[15] K. Beegle, E. Frankenberg, and D. Thomas, "Bargaining power within couples and use of prenatal and delivery care in Indonesia," Studies in Family Planning, vol. 32, no. 2, pp. 130-146, 2001.

[16] W. H. Greene, "Gender economics courses in liberal arts colleges: further results," Journal of Economic Education, vol. 29, no. 4, pp. 291-300, 1998.

[17] C. Monfardini and R. Radice, "Testing exogeneity in the bivariate probit model: a monte carlo study," Oxford Bulletin of Economics and Statistics, vol. 70, no. 2, pp. 271-282, 2008.

[18] B. R. Humphreys, J. A. Nyman, and J. E. Ruseski, “The effect of gambling on health: evidence from Canada," Working Paper 2011-18, Department of Economics, University of Alberta, Alberta, Canada, 2011.

[19] Y. Kamiya, Endogenous women's autonomy and the use of reproductive health services: empirical evidence from Tajikistan [Ph.D. thesis], Osaka School of International Public Policy, Osaka University, Osaka, Japan, 2010. 


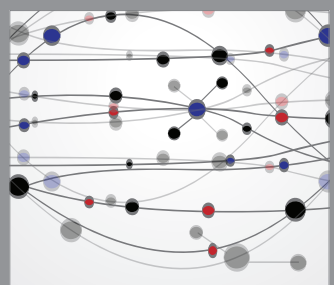

The Scientific World Journal
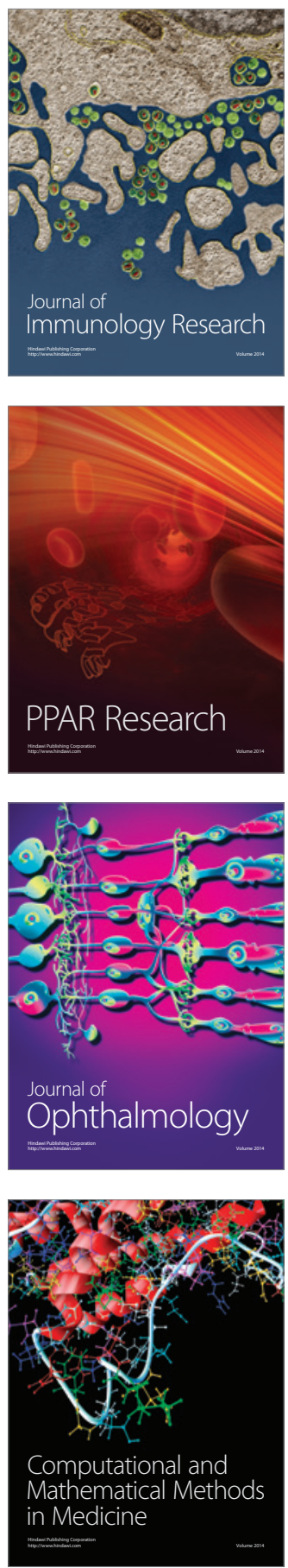

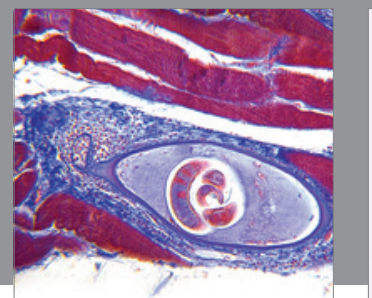

Gastroenterology

Research and Practice
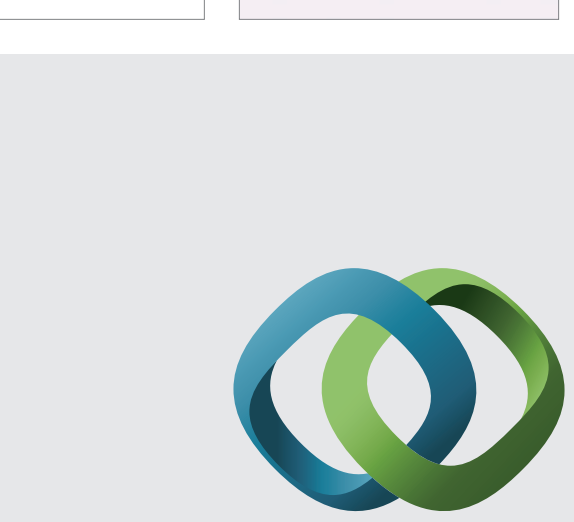

\section{Hindawi}

Submit your manuscripts at

http://www.hindawi.com
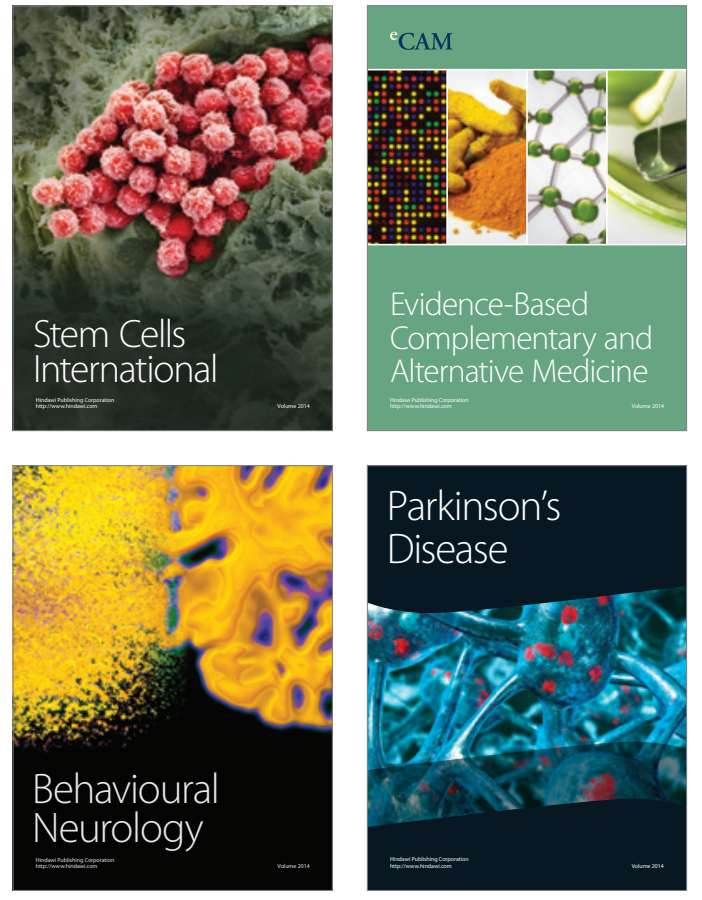
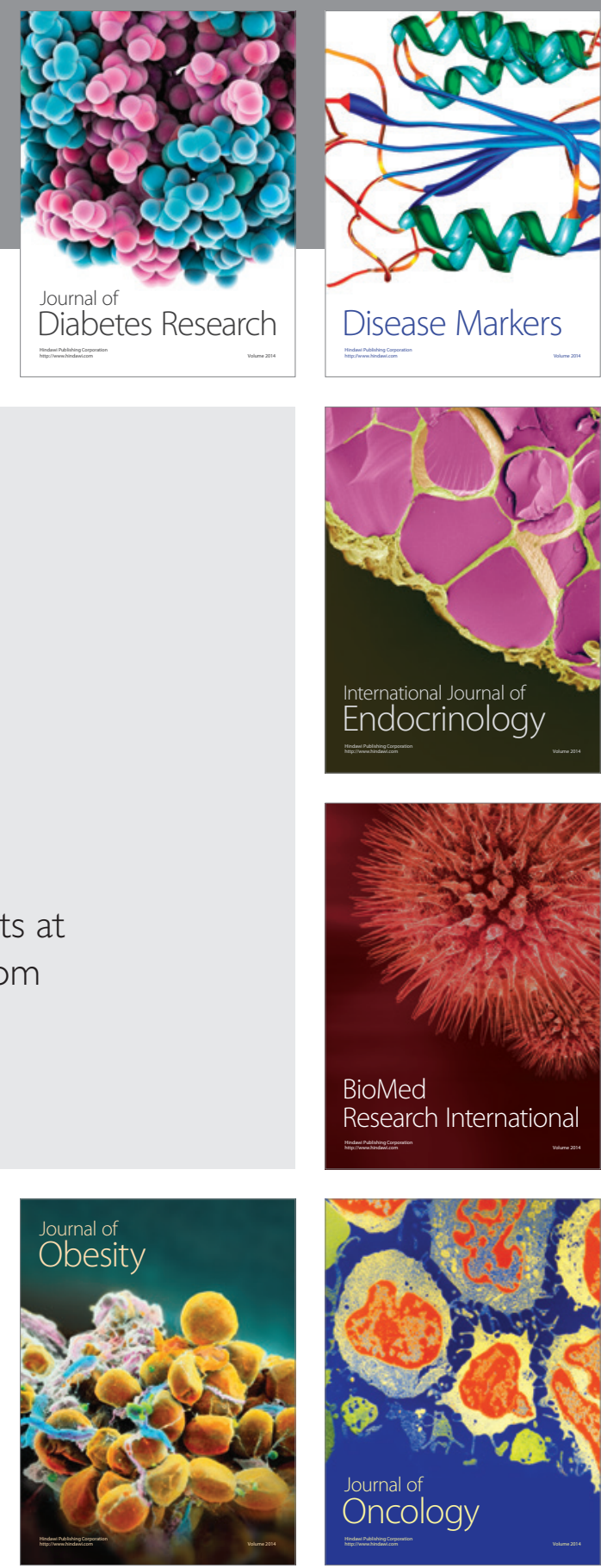

Disease Markers
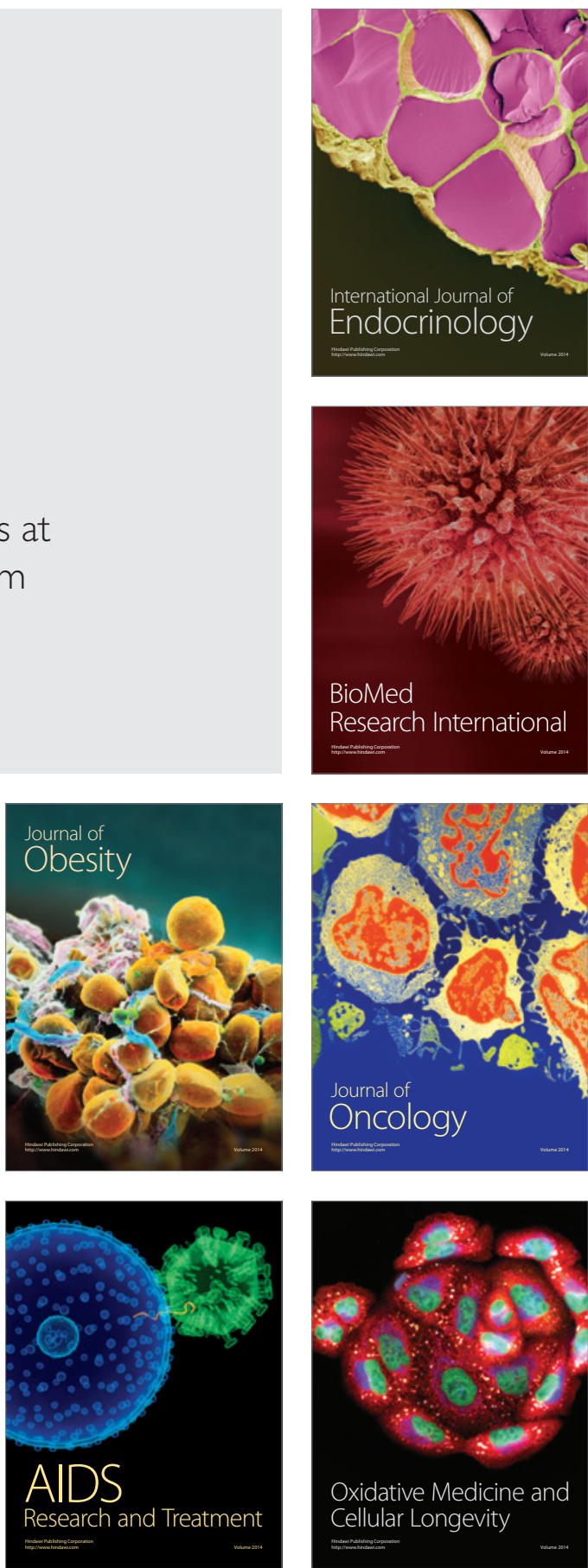